\section{Pathophysiology \\ of Haemostasis and Thrombosis}

Pathophysiol Haemost Thromb 2005;34:156-159

DOI: $\underline{10.1159 / 000092415}$

\title{
Structure-Function Relationships of C-Type Lectin-Related Proteins
}

\author{
Takashi Morita \\ Department of Biochemistry, Meiji Pharmaceutical University, Noshio, Kiyose, Tokyo, Japan
}

\section{Key Words \\ C-type lectin-like protein - Three-dimensional domain swapping • Blood coagulation factor IX/ factor X-binding protein (IX/X-bp) • EMS-16 • Collagen receptor antagonist}

\begin{abstract}
The structural and functional studies of the first identified C-type lectin-like protein (CLP), blood coagulation factor IX/factor X-binding protein (IX/X-bp), have been instrumental in defining how new functionally heterodimeric CLPs are generated from monomeric carbohydrate recognition domain in C-type lectins by three-dimensional domain swapping. The crystal structures of $\gamma$-carboxyglutamic acid domains of coagulation factors $X$ and IX have recently been clarified in structural studies of complexes between the $\gamma$-carboxyglutamic acid domain of factors $X$ and $X$-bp (a venom CLP) and between the $\gamma$-carboxyglutamic acid domain of factors IX and IXbp (a venom CLP).
\end{abstract}

Copyright $@ 2005$ S. Karger AG, Basel

\section{Introduction}

Snake venoms contain proteins that both activate and inhibit blood coagulation factors. It was reported in 1972-1975 that the venoms of Deinagkistrodon acutus (formerly Agkistrodon acutus) [1] and Trimeresurus stejnegeri (formerly Trimeresurus gramineus) [2] contain proteins that inhibit prothrombin activation possibly by nonenzymatic mechanisms $[3,4]$. One of the anticoagulants in the venom of $D$. acutus was characterized as a factor X-binding protein (X-bp) in 1989, and the venom of Trimeresurus flavoviridis (Habu snake) was also found to contain another factor X-bp with anticoagulant activity [5]. Furthermore, this $T$. flavoviridis anticoagulant protein binds not only factors $\mathrm{X}$ and $\mathrm{Xa}$, but also to factors IX and IXa [5].

IX/X-bp was identified as the first protein of the C-type lectin-like protein (CLP) class in 1991 [6]. RVV$\mathrm{X}$, factor $\mathrm{X}$ activator from Russell's viper venom, was sequenced in 1992 [7] and found to be a CLP with a C-type lectin-like domain within its light chain. The platelet agonist botrocetin was identified as a CLP with no lectin activity in 1993 [8]. Several more CLPs have been isolated from various snake venoms, sequenced, and found to have a variety of biological activities over the last 15 years [9-14]. It is now clear that the CLPs form a new protein family, and that they are useful tools for elucidating the complex mechanisms involved in clotting and platelet activation, as well as for determining the structure-function relationship of both blood clotting factors and human platelet glycoproteins [14].

\section{Basic Structures of C-Type Lectin-Like Proteins}

Table 1 shows a list of the representative CLPs affecting the hemostatic system, including anticoagulants, coagulants, and platelet modulators (agonist and antagonists) with no lectin activity. Many biologically active

\section{KARGER \\ Fax +41613061234 E-Mail karger@karger.ch} www.karger.com
C 2005 S. Karger AG, Basel

$1424-8832 / 05 / 0345-0156 \$ 22.00 / 0$

Accessible online at: www.karger.com/pht
Takashi Morita, $\mathrm{PhD}$

Department of Biochemistry, Meiji Pharmaceutical University

2-522-1, Noshio, Kiyose

Tokyo 204-8588 (Japan)

Tel./Fax+8142495 8479, E-Mail tmorita@my-pharm.ac.jp 
Table 1. C-type lectin-like proteins (CLPs) of snake venom that modulate the hemostatic system

\begin{tabular}{llll}
\hline Function & CLP & Structure & $\begin{array}{l}\text { Ligand protein } \\
\text { or substrate }\end{array}$ \\
\hline Anticoagulant & IX/X-bp, IX-bp & $\alpha \beta$ & Factor IX \\
& IX/X-bp, X-bp & $\alpha \beta$ & Factor X \\
& bothrojaracin & $\alpha \beta$ & $\alpha$-Thrombin \\
\hline Coagulant & RVV-X & $\alpha \beta /$ metalloprotease & Factor X \\
& carinactivase-1 (CA-1) & $\alpha \beta /$ metalloprotease & Prothrombin \\
\hline Agonist of platelet & botrocetin, bitiscetin & $\alpha \beta$ & vWF \\
& alboaggregin-B & $\alpha \beta$ & GPIb $\alpha$ \\
& aggregin/rhodocytin & $\alpha \beta$ & GPIa/IIa \\
& convulxin & $(\alpha \beta)_{4}$ & GPVI \\
& agglucetin & tetrameric structure* & GPIb $\alpha$ \\
\hline Antagonist of platelet & EMS 16 & $\alpha \beta$ & GPIa/IIa \\
& echicetin & $\alpha \beta$ & GPIb $\alpha$ \\
& flavocetin-A (FL-A) & $(\alpha \beta)_{4}$ & GPIb $\alpha$ \\
\hline
\end{tabular}

* Hypothetical construct may be tetrameric $\left(\alpha_{1}-\beta_{2}-\alpha_{2}-\beta_{1}\right)$ structure [24].

CLPs consist of one or more heterodimers of two C-type lectin-like subunits. These CLPs include the anticoagulant proteins blood coagulation factor IX/factor X-binding protein (IX/X-bp), IX-bp, and X-bp, which contain disulfide-linked heterodimers of C-type lectin-like subunits. Another CLP, bothrojaracin, is a hirudin-like thrombin inhibitor with anticoagulant activity [15]. Its biological activity is $\mathrm{Ca}^{2+}$-independent, in contrast to the $\mathrm{Ca}^{2+}$-dependent CLP anticoagulants. RVV-X and carinactivase-1 (CA-1) are metalloenzymes composed of two C-type lectin-like domains that recognize the $\gamma$-carboxyglutamic acid (Gla) domains of factor X and prothrombin, respectively $[16,17]$. Other CLP effectors of platelet function include botrocetin [8] and bitiscetin [18, 19], which are von Willebrand factor (vWF)-binding aggregation inducers, and alboaggregin-B, a platelet GPIb-binding inducer of aggregation [20,21].

The basic structure of the CLPs includes two homologous subunits: subunit $\alpha$ (A chain), of $14-15 \mathrm{kDa}$, and subunit $\beta$ (B chain), of $13-14 \mathrm{kDa}$. The CLPs are composed of a variety of oligomeric forms, including $\alpha \beta$, $(\alpha \beta)_{2}$, or $(\alpha \beta)_{4}[6,22-24]$. In CLPs of snake venom, the basic $\alpha \beta$ dimer is formed by domain swapping (see next section). In contrast, C-type lectins, such as the lectin from the venom of Crotalus atrox, are made up of homodimers or homooligomers [25].

\section{Dimerization of CLP by Domain Swapping Mechanism}

One of the functional components of snake venom is now known to be a member of the C-type lectin-like protein family that includes IX/X-bp, CA-1, RVV-X, botocetin, and flavocetin-A. The crystal structures of habu IX/X-bp [26], habu IX-bp [27] and acutus X-bp [28] indicate that each subunit of these proteins has a $\mathrm{Ca}^{2+}$-binding site, different from that of C-type lectins such as mannose-binding protein (MBP), and that dimerization involves swapping of the central loop of these subunits [26]. Dimerization of the carbohydrate recognition domain (CRD) in C-type lectins by three-dimensional (3D) domain swapping generates novel proteins with new functions such as coagulant-, anticoagulant-, or platelet-modulating activities.

The first IX/X-bp crystal structure revealed 3D domain swapping [26]. A domain from the $\alpha$ subunit replaces the essentially identical domain in the $\beta$ subunit. At the same time, this domain from the $\beta$ subunit is swapped for the same domain in the $\alpha$ subunit. A prominent feature of this structure is the projection of a central portion of the polypeptide chain towards the adjoining subunit, forming a tight dimer association. Excluding this feature, each subunit has a fold similar to the C-type CRD fold of MBP. The polypeptide chain then extends from the surface of the subunit, forming a large open loop that 
project into the adjoining subunit, forming a loop-exchanged dimer, whereas the MBP chain in this region is folded back onto the subunit. In this way, the two subunits form an intertwined dimer with swapped domains.

The swapped and hinge region of the $\alpha$ subunit extends away from the surface of the subunits and forms a large open loop that projects into the adjoining subunit. This generates a loop-exchange dimer. In contrast, the equivalent loop in MBP folds back onto the subunit. Similar structural features occur in the $\beta$ subunit of IX/X-bp. The extended loop of IX/X-bp returns to the main body of the subunit. Thus, subunit A generates a structure that is homologous to that of MBP by 'borrowing' the open loop of the adjoining subunit B. Similar structural features occur in subunit B. Thus, dimerization may be closely related to a function completely different from that of the 'monomer' motif C-type CRD, suggesting economic use of combinations of limited structural domains. Generally, the structures of both proteins are built up from a common frame. The open loop donated to the $\alpha$ subunit by the adjoining $\beta$ subunit coincides structurally with the folded-back loop of MBP. Hence, the $\alpha$ subunit generates a structure that is homologous to that of MBP by borrowing the open loop of the adjoining $\beta$ subunit. Most swapped domains of proteins are at either the $\mathrm{N}$ - or C-terminus. The only exception found to date is IX/X-bp in which the two subunits of IX/X-bp form a heterodimer by exchanging a loop in their central regions [29]. In addition, IX/Xbp is the only known example of a domain-swapped heterodimer; all other domain-swapped proteins are homodimers or homooligomers [29]. Thus, to be precise, $\mathrm{IX} / \mathrm{X}-\mathrm{bp}$ is quasi-domain-swapped.

This novel structure and function of proteins in snake venom serves as a strategy for survival against animal predators, and represents an evolutionary gain of function for the C-type CRD domain [26].

\section{Structure-Function Relationship of CLP}

The CLP family includes the anticoagulant proteins habu IX/X-bp (factor IX/factor X-binding protein), habu IX-bp (factor IX-binding protein), and acutus X-bp (factor X-binding protein), which contain disulfide-linked heterodimers of CLP subunits [5, 6, 26-28, 30-32]. Apparent dissociation constants for the binding of habu IX/ $\mathrm{X}$-bp to factor IX and factor $\mathrm{X}$ are 0.4 and $1.1 \mathrm{n} M$, respectively, in the presence of $\mathrm{Ca}^{2+}$ ions, indicating that these CLPs have quite high affinities for these coagulation factors. These CLPs have strong anticoagulant activities due to their binding to Gla-containing domains of coagulation factors IX and $\mathrm{X}$ in the presence of calcium ions $[32,33]$. The functionally important Gla domain binds to the concave surface in X-bp. Thus, the strong anticoagulant activity of X-bp is due to its binding at the Gla domain of factor $\mathrm{X}$. The formation of this complex appears to block efficiently the membrane interaction of the Gla domain that is essential for amplification of the coagulation cascade [28].

There are several other unique CLPs that act as agonists and antagonists of platelet receptors, platelet glycoprotein Ib and glycoproteins Ia/IIa and VI, the collagen receptors. These CLPs may provide new insights into platelet function. EMS16, a CLP, is an antagonist of collagen receptor (GPIa/IIa), that is, a potent and selective inhibitor of the $\alpha 2 \beta 1$ integrin [34-36]. The crystal structure of EMS16 in complex with the integrin $\alpha 2$-I domain provides new information about the structure-function relationship of CLPs [37]. The structure of the EMS16 in complex with the integrin $\alpha 2$-I domain at $1.9 \AA$ resolution reveals that the collagen-binding site of the $\alpha 2$-I domain is covered completely by the bound EMS16 [37]. This blockage by EMS16 inhibits collagen binding to the $\alpha 2-\mathrm{I}$ domain. The complex structure reveals that the collagenbinding site of the $\alpha 2$-I domain lies on the concave surface of EMS16, and there are direct binding sites at both ends of this surface. Binding takes place mainly through van der Waal's interactions, suggesting that EMS16 inhibits by blocking the collagen-binding site of the $\alpha 2$-I domain. The crystal structure of EMS16 in complex with the integrin $\alpha 2$-I domain may provide new information for the development of more effective antagonists against integrin $\alpha 2 \beta 1$ [37].

\section{Conclusions}

CLPs of snake venom such as IX/X-bp and its structurally-related proteins adapt to recognize various ligands by the higher frequency of mutation in the open reading frames than in the noncoding regions after duplication of a gene. The existence of such accelerated duplication and mutation of genes could mean that similar processes for the A and B chains of IX/X-bp and of other CLPs might have resulted in the present family of heterodimeric CLPs that includes IX/X-bp and various other proteins that are structurally related to but yet functionally distinct from one another. 


\section{References}

$\checkmark 1$ Ouyang C, Teng CM: Purification and properties of the anticoagulant principle of Agkistrodon acutus venom. Biochim Biophys Acta 1972;278:155-162.

$>2$ Ouyang C, Yang FY: Purification and properties of the anticoagulant principle of Trimeresurus gramineus venom. Biochim Biophys Acta 1975;386:479-492.

$\checkmark 3$ Ouyang C, Teng CM: The effect of the purified anticoagulant principle of Agkistrodon acutus venom on blood coagulation. Toxicon 1973; 11:287-292.

-4 Teng CM, Seegers WH: Agkistrodon acutus snake venom inhibits prothrombinase complex formation. Thromb Res 1981;23:255263.

$>5$ Atoda H, Morita T: A novel blood coagulation factor IX/factor X-binding protein with anticoagulant activity from the venom of Trimeresurus flavoviridis (Habu snake): isolation and characterization. J Biochem (Tokyo) 1989; 106:808-813.

$\checkmark 6$ Atoda H, Hyuga M, Morita T: The primary structure of coagulation factor IX/factor Xbinding protein isolated from the venom of Trimeresurus flavoviridis. Homology with asialoglycoprotein receptors, proteoglycan core protein, tetranectin, and lymphocyte Fce receptor for immunoglobulin E. J Biol Chem 1991;266:14903-14911.

77 Takeya H, Nishida S, Miyata T, Kawada S, Saisaka Y, Morita T, Iwanaga S: Coagulation factor X activating enzyme from Russell's viper venom (RVV-X). A novel metalloproteinase with disintegrin (platelet aggregation inhibitor)-like and C-type lectin-like domains. J Biol Chem 1992;267:14109-14117.

$>8$ Usami Y, Fujimura Y, Suzuki M, Ozeki Y, Nishio K, Fukui H, Titani K: Primary structure of two-chain botrocetin, a von Willebrand factor modulator purified from the venom of Bothrops jararaca. Proc Natl Acad Sci USA 1993;90:928-932.

$\checkmark 9$ Sekiya F, Atoda H, Morita T: Isolation and characterization of an anticoagulant protein homologous to botrocetin from the venom of Bothrops jararaca. Biochemistry 1993;32: 6892-6897.

10 Chen YL, Tsai IH: Functional and sequence characterization of coagulation factor IX/factor X-binding protein from the venom of Echis carinatus leucogaster. Biochemistry 1996;35:5264-5271.

- 11 Usami Y, Suzuki M, Yoshida E, Sakurai Y, Hirano K, Kawasaki T, Fujimura Y, Titani K: Primary structure of alboaggregin-B purified from the venom of Trimeresurus albolabris. Biochem Biophys Res Commun 1996;219: 727-733.
12 Drickamer K: C-type lectin-like domains. Curr Opin Struct Biol 1999;9:585-590.

13 Morita T: C-type lectin-related proteins from snake venoms. Curr Drug Targets - Cardiovasc Haematol Disord 2004; 357-373.

14 Morita T: Use of snake venom inhibitors in studies of the function and tertiary structure of coagulation factors. Int J Hematol 2004;79: 123-129.

15 Zingali RB, Jandrot-Perrus M, Guillin MC, Bon C: Bothrojaracin, a new thrombin inhibitor isolated from Bothrops jararaca venom: characterization and mechanism of thrombin inhibition. Biochemistry 1993;32:10794-10802.

16 Yamada D, Sekiya F, Morita T: Isolation and characterization of carinactivase, a novel prothrombin activator in Echis carinatus venom with a unique catalytic mechanism. J Biol Chem 1996;271:5200-5207.

17 Morita T: Proteases which activate factor X; in Bailey GS (ed): Snake Venom Enzymes, Fort Collins, Alaken, Inc., 1998, pp 179-208.

18 Hamako J, Matsui T, Suzuki M, Ito M, Makita K, Fujimura Y, Ozeki Y, Titani K: Purification and characterization of bitiscetin, a novel von Willebrand factor modulator protein from Bitis arietans snake venom. Biochem Biophys Res Commun 1996;226:273-279.

19 Matsui T, Hamako J, Matsushita T, Nakayama T, Fujimura Y, Titani K: Binding site on human von Willebrand factor of bitiscetin, a snake venom-derived platelet aggregation inducer. Biochemistry 2002;41:7939-7946.

20 Peng M, Lu W, Kirby EP: Alboaggregin-B: a new platelet agonist that binds to platelet membrane glycoprotein Ib. Biochemistry 1991;30: 11529-11536.

21 Yoshida E, Fujimura Y, Miura S, Sugimoto M, Fukui H, Narita N, Usami Y, Suzuki M, Titani $\mathrm{K}$ : Alboaggregin-B and botrocetin, two snake venom proteins with highly homologous amino acid sequences but totally distinct functions on von Willebrand factor binding to platelets. Biochem Biophys Res Commun 1993;191: 1386-1392.

22 Fukuda K, Mizuno H, Atoda H, Morita T: Crystal structure of flavocetin-A, a platelet glycoprotein Ib-binding protein, reveals a novel cyclic tetramer of C-type lectin-like heterodimers. Biochemistry 2000;39:1915-1923.

23 Wang WJ, Huang TF: A novel tetrameric venom protein, agglucetin from Agkistrodon acutus, acts as a glycoprotein $\mathrm{Ib}$ agonist. Thromb Haemost 2001;86:1077-1086.

24 Wang WJ, Ling QD, Liau MY, Huang TF: A tetrameric glycoprotein Ib-binding protein, agglucetin, from Formosan pit viper: structure and interaction with human platelets. Thromb Haemost 2003;90:465-475.

-25 Hirabayashi J, Kusunoki T, Kasai K: Complete primary structure of a galactose-specific lectin from the venom of the rattlesnake Crotalus atrox. Homologies with $\mathrm{Ca}^{2+}$-dependenttype lectins. J Biol Chem 1991;266:23202326.
26 Mizuno H, Fujimoto Z, Koizumi M, Kano H, Atoda H, Morita T: Structure of coagulation factors IX/X-binding protein, a heterodimer of C-type lectin domains. Nat Struct Biol 1997; 4: 438-441.

27 Mizuno H, Fujimoto Z, Koizumi M, Kano H, Atoda H, Morita T: Crystal structure of coagulation factor IX-binding protein from habu snake venom at $2.6 \mathrm{~A}$ : implication of central loop swapping based on deletion in the linker region. J Mol Biol 1999;289:103-112.

28 Mizuno H, Fujimoto Z, Atoda H, Morita T: Crystal structure of an anticoagulant protein in complex with the Gla domain of factor X. Proc Natl Acad Sci USA 2001;98:7230-7234.

29 Liu Y, Eisenberg D: 3D domain swapping: as domains continue to swap. Protein Sci 2002; 11:1285-1299.

-30 Shikamoto Y, Morita T, Fujimoto Z, Mizuno $\mathrm{H}$ : Crystal structure of $\mathrm{Mg}^{2+}$ - and $\mathrm{Ca}^{2+}$-bound Gla domain of factor IX complexed with binding protein. J Biol Chem 2003;278:2409024094.

31 Atoda H, Morita T: Arrangement of the disulfide bridges in a blood coagulation factor IX/ factor X-binding protein from the venom of Trimeresurus flavoviridis. J Biochem (Tokyo) 1993; 113:159-163.

32 Atoda H, Yoshida N, Ishikawa M, Morita T: Binding properties of the coagulation factor $\mathrm{IX} /$ factor X-binding protein isolated from the venom of Trimeresurus flavoviridis. Eur J Biochem 1994;224:703-708

33 Atoda H, Ishikawa M, Mizuno H, Morita T: Coagulation factor X-binding protein from Deinagkistrodon acutus venom is a Gla domain-binding protein. Biochemistry 1998;37: 17361-17370.

34 Marcinkiewicz C, Lobb RR, Marcinkiewicz MM, Daniel JL, Smith JB, Dangelmaier C, Weinreb PH, Beacham DA, Niewiarowski S: Isolation and characterization of EMS16, a Clectin type protein from Echis multisquamatus venom, a potent and selective inhibitor of the $\alpha 2 \beta 1$ integrin. Biochemistry 2000;39:98599867.

35 Okuda D, Horii K, Mizuno H, Morita T: Characterization and preliminary crystallographic studies of EMS16, an antagonist of collagen receptor (GPIa/IIa) from the venom of Echis multisquamatus. J Biochem (Tokyo) 2003; 134:19-23.

36 Horii K, Okuda D, Morita T, Mizuno H: Structural characterization of EMS16, an antagonist of collagen receptor (GPIa/IIa) from the venom of Echis multisquamatus. Biochemistry 2003;42:12497-12502.

- 37 Horii K, Okuda D, Morita T, Mizuno H: Crystal structure of EMS16 in complex with the integrin $\alpha 2$-I domain. J Mol Biol 2004;341:519527. 